\title{
Current discharge management of acute coronary syndromes: data from the Rijnmond Collective Cardiology Research (CCR) study
}

\author{
T. Yetgin • M. M. J. M. van der Linden • A. G. de Vries • P. C. Smits • \\ R. van Mechelen • S. C. Yap • E. Boersma • F. Zijlstra • \\ R.-J. M. van Geuns • on behalf of the CCR Study Investigators
}

Published online: 24 October 2013

(C) The Author(s) 2013. This article is published with open access at Springerlink.com

\begin{abstract}
Background Medical discharge management of acute coronary syndromes (ACS) remains suboptimal outside randomised trials and constitutes an essential quality benchmark for ACS. We sought to evaluate the rates of key guideline-recommended pharmacological agents after ACS and characteristics associated with optimal treatment at discharge.

Methods The Rijnmond Collective Cardiology Research (CCR) registry is an ongoing prospective, observational study in the Netherlands that aims to enrol 4000 patients with ACS. We examined discharge and 1-month follow-up medication use among the first 1000 patients enrolled in the CCR registry. Logistic regression was performed to identify patient and
\end{abstract}

Member hospitals are listed in Appendix A.

T. Yetgin · M. M. J. M. van der Linden · S. C. Yap · E. Boersma • F. Zijlstra $\cdot$ R.-J. M. van Geuns

Department of Cardiology, Erasmus MC, Thoraxcentre,

Room Ee-2355, Dr. Molewaterplein 50-60,

3015 GE Rotterdam, The Netherlands

M. M. J. M. van der Linden $(\square)$

Department of Cardiology, Vlietland Hospital, Vlietlandplein 2,

3118 JH Schiedam, The Netherlands

e-mail: mvdlinden@vlietlandziekenhuis.nl

A. G. de Vries

Department of Cardiology, Albert Schweitzer Hospital, Albert

Schweitzerplaats 25, 3318 AT Dordrecht, The Netherlands

P. C. Smits

Department of Cardiology, Maasstad Hospital, Maasstadweg 21,

3079 DZ Rotterdam, The Netherlands

R. van Mechelen

Department of Cardiology, Sint Franciscus Gasthuis,

Kleiweg 500, 3045 PM Rotterdam, The Netherlands hospital characteristics associated with collective guidelinerecommended pharmacotherapy at hospital discharge. Results At discharge, $94 \%$ of patients received aspirin, $100 \%$ thienopyridines, $80 \%$ angiotensin-converting enzyme inhibitors/angiotensin-II receptor blockers, $87 \% \beta$-blockers, $96 \%$ statins, and $65 \%$ the combination of all 5 agents. STsegment elevation myocardial infarction, hypertension, hypercholesterolaemia, and enrolment in an interventional centre were positive independent predictors of 5-drug combination therapy at discharge. Negative independent predictors were unstable angina and advanced age.

Conclusion Current data from the CCR registry reflect a high quality of care for ACS discharge management in the

S. C. Yap

Department of Cardiology, Erasmus MC, Thoraxcentre, Room Ba-316, 's-Gravendijkwal 230, 3015 CE Rotterdam, The Netherlands

E. Boersma

Department of Cardiology, Erasmus MC, Thoraxcentre, Room Bd-381, 's-Gravendijkwal 230, 3015 CE Rotterdam, The Netherlands

R.-J. M. van Geuns

Department of Cardiology, Erasmus MC, Thoraxcentre, Room Ba-585, 's-Gravendijkwal 230, 3015 CE Rotterdam, The Netherlands

\section{F. Zijlstra}

Department of Cardiology, Erasmus MC, Thoraxcentre, Room Ba-593, 's-Gravendijkwal 230, 3015 CE Rotterdam, The Netherlands 
Rotterdam-Rijnmond region. However, potential still remains for further optimisation.

Keywords Acute coronary syndrome $\cdot$ Percutaneous coronary intervention $\cdot$ Post-discharge medication

\section{Introduction}

Acute coronary syndrome (ACS) remains a major cause of morbidity and mortality in the Western world. Despite the use of percutaneous coronary intervention (PCI) for acute management of ACS, patients are still at risk for recurrent cardiovascular events $[1,2]$. In this regard, antiplatelet agents, angiotensin-converting enzyme inhibitors (ACE-I) or angiotensin II receptor blockers (ARB), $\beta$-blockers, and lipidlowering agents are individually effective in reducing secondary cardiovascular events, and even more effective when combined together [2].

The guidelines of the European Society of Cardiology on the management of non-ST-segment elevation acute coronary syndromes (NSTE-ACS) [3] and ST-segment elevation myocardial infarction (STEMI) [4, 5], as well as the American College of Cardiology/American Heart Association guidelines recommend the collective use of these pharmacological agents for long-term treatment of patients after ACS [6]. Moreover, the prescription of these classes of agents at discharge is used as performance measures for patients with both ST-segment elevation and non-ST-segment elevation myocardial infarction [3, 7]. Nevertheless, there is evidence to suggest that patients with ACS are still not optimally managed with the aforementioned combination of agents after an acute coronary event [8].

Accordingly, the purpose of the current study was to determine the individual and collective prescription rates of the 5 key guideline-recommended therapies (aspirin, thienopyridines, ACE-I/ARBs, $\beta$-blockers, and statins) after hospital discharge and adherence at 1-month follow-up in the first subset of 1000 ACS patients from the ongoing Rijnmond Collective Cardiology Research (CCR) registry. At the same time, this will serve as a baseline measurement for discharge management of ACS in our region, an important performance indicator of quality of care. We also sought to evaluate patient and practice characteristics associated with the collective use of these agents.

\section{Methods}

Study design and population

Full details of the CCR study (Dutch Trial Register unique identifier: NTR3704) rationale and methodology are reported in the present issue of the Netherlands Heart Journal [9] along with the current report. In brief, the CCR study is a prospective, multicentre, observational registry of management practices and outcome of ACS up to 12 months postdischarge. Eligible patients are $(1) \geq 18$ years of age on presentation; (2) diagnosed with NSTE-ACS or STEMI and treated with PCI during index hospitalisation. The only exclusion criterion is intolerance for aspirin, clopidogrel or prasugrel. Currently, 11 member sites of the CCR network in the Rotterdam-Rijnmond region in the Netherlands (Appendix) are participating in this observational study. Enrolment will continue until the intended number of 4000 patients is recruited. The CCR registry was initiated after updating treatment guidelines of the participating network to include prasugrel as the first-line treatment option for antiplatelet therapy.

Patient characteristics, clinical features, angiographic and procedural details, and in-hospital outcomes were abstracted from the medical chart per routine and entered into a secure web-based and centralised database by enrolling site personnel. After the index hospitalisation, patients were routinely followed up at 1 month and 12 months at the outpatient clinics of the enrolling sites, after which information on medication use and clinical outcomes was collected and entered into the central database. In the current study, continued adherence was assessed by patient report as provided during the 1month follow-up visit.

The current study cohort was restricted to the first consecutive 1000 ACS patients enrolled in the CCR study who were alive at 1-month follow-up with complete follow-up data on discharge medications. These patients were recruited between August 2011 and February 2012.

\section{Pharmacotherapy}

The 5 key guideline-recommended therapies of interest were aspirin, thienopyridines, ACE-I/ARBs, $\beta$-blockers, and statins. For the purpose of the present analysis, patients were divided into two subsets: those receiving all 5 pharmacological agents at discharge versus patients not receiving the 5drug combination.

\section{Ethics}

Patients were not subjected to acts or imposed to any mode of behaviour for the purpose of this study, other than standard treatment. Therefore, according to Dutch law, written informed consent for a patient to be enrolled in this study was not required. All patients provided oral assurance of their willingness to participate in the current study. This study is conducted according to the Privacy Policy of the Erasmus MC and according to the Erasmus MC regulations for the appropriate use of data in patient-oriented research, 
and is approved by the regional ethics committee (reference \# MEC-2010-417).

\section{Statistical analysis}

Continuous variables are summarised as mean \pm standard deviation (SD) or median with interquartile range (IQR), depending on normal distribution and were compared using the Student $t$-test or Mann-Whitney $U$-test as appropriate. Categorical variables are summarised as percentages and were compared using the chi-square test. The McNemar test was used for pairwise comparisons of discharge and follow-up medication use. The primary study outcome was the collective discharge prescription of aspirin, thienopyridines, ACE-I/ ARBs, $\beta$-blockers, and statins. Multivariable logistic regression was performed to identify patient and hospital characteristics independently associated with the collective use of the aforementioned 5 evidence-based agents using the forward selection method. The following candidate variables associated with the 5-drug combination therapy at discharge on univariate analyses $(p<0.05)$ were entered into the model: age, diabetes, hypertension, hypercholesterolaemia, family history of coronary artery disease, previous coronary artery bypass grafting (CABG), enrolment into the registry at the interventional centre, unstable angina (UA), and STEMI. Model discrimination was evaluated by the c-statistic and calibration by the Hosmer-Lemeshow goodness-of-fit test.

All analyses were performed using SPSS version 20 (SPSS, Inc., Chicago, Illinois, USA) and two-tailed $P$-values $<0.05$ were considered to indicate statistical significance.

\section{Results}

The baseline characteristics of the study cohort are presented in Table 1. The mean age was $63.7 \pm 12.5$ years, and $72.2 \%$ were men. The most commonly documented comorbidities or risk factors present at the time of admission for the index ACS event included hypertension, family history of coronary artery disease, and smoking. Approximately $42 \%$ presented with
Table 1 Baseline demographic and clinical characteristics
CABG indicates coronary artery bypass grafting; $H F$ heart failure; $M I$ myocardial infarction; NSTEMI non-ST-segment elevation myocardial infarction; $P C I$ percutaneous coronary intervention; STEMI ST-segment elevation myocardial infarction; TIA transient ischaemic attack; and $U A$ unstable angina

${ }^{a}$ Combination therapy is defined as the collective use of aspirin, thienopyridines, angiotensinconverting enzyme inhibitors or angiotensin II receptor blockers, $\beta$-blockers, and statins

\begin{tabular}{|c|c|c|c|c|}
\hline Characteristics & $\begin{array}{l}\text { All patients } \\
(N=1000)\end{array}$ & $\begin{array}{l}\text { Patients receiving } \\
5 \text {-drug combination } \\
\text { therapy at discharge } \\
(N=652)\end{array}$ & $\begin{array}{l}\text { Patients not receiving } \\
5 \text {-drug combination } \\
\text { therapy a at discharge } \\
(N=348)\end{array}$ & $P$ \\
\hline Age, mean (SD) & $63.7(12.5)$ & $62.6(12.5)$ & $65.9(12.3)$ & $<0.001$ \\
\hline Male gender (\%) & 72.2 & 72.8 & 70.9 & 0.53 \\
\hline \multicolumn{5}{|l|}{ Risk factors (\%) } \\
\hline - Diabetes & 18.3 & 20.1 & 14.6 & 0.04 \\
\hline - Hypertension & 50.1 & 54.9 & 40.6 & $<0.001$ \\
\hline - Hypercholesterolaemia & 36.4 & 40.2 & 29.4 & 0.001 \\
\hline - Current smoker & 37.2 & 38.2 & 37.5 & 0.86 \\
\hline - Family history & 45.6 & 50.6 & 42.7 & 0.02 \\
\hline \multicolumn{5}{|l|}{ Medical history (\%) } \\
\hline - Previous MI & 19.1 & 19.6 & 18.2 & 0.59 \\
\hline - Previous HF & 3.9 & 3.4 & 5.1 & 0.20 \\
\hline - Previous CABG & 5.5 & 4.5 & 7.6 & 0.05 \\
\hline - Previous PCI & 19.6 & 19.9 & 19.0 & 0.76 \\
\hline - Previous stroke/TIA & 7.0 & 7.0 & 7.0 & 0.97 \\
\hline $\begin{array}{l}\text { Enrolment in interventional } \\
\text { centre }(\%)\end{array}$ & 42.0 & 46.2 & 32.9 & $<0.001$ \\
\hline Admission length (days) & $4(3-6)$ & $4(4-6)$ & $4(3-7)$ & 0.07 \\
\hline Ejection fraction & & & & $<0.001$ \\
\hline - Normal $(\geq 50 \%)$ & 69.0 & 65.6 & 76.1 & \\
\hline - Moderate (30-49\%) & 26.8 & 31.1 & 17.7 & \\
\hline - Poor $(<30 \%)$ & 4.2 & 3.3 & 6.2 & \\
\hline Time from admission to PCI (days) & $0(0-2)$ & $0(0-2)$ & $1(0-3)$ & $<0.001$ \\
\hline \multicolumn{5}{|l|}{ Discharge diagnosis $(\%)$} \\
\hline - UA & 26.6 & 21.8 & 37.0 & $<0.001$ \\
\hline - NSTEMI & 31.2 & 30.1 & 33.5 & 0.28 \\
\hline - STEMI & 42.2 & 48.1 & 29.4 & $<0.001$ \\
\hline
\end{tabular}


STEMI, $31 \%$ with non-ST-segment elevation myocardial infarction, and $27 \%$ with UA. A total of 652 ACS patients (65\%) received all 5 guideline-recommended classes of pharmacological agents at discharge. These patients were younger, more likely to have diabetes, hypertension, hypercholesterolaemia, and a family history of coronary artery disease, and more likely to be diagnosed with STEMI and enrolled to the registry in an interventional centre. In contrast, patients receiving the collective prescription of aforementioned agents were less likely to have previous CABG and less likely to be diagnosed with UA.

Figure 1 depicts the discharge prescription rates and medication use at follow-up in the study cohort according to ACS spectrum. Institutional discharge and follow-up prescription rates are presented in Figs. 2 and 3, respectively. At discharge, $94.0 \%$ of the overall study patients were prescribed aspirin, $99.8 \%$ thienopyridines, $8.0 \%$ oral anticoagulants, $80.3 \%$ ACE-I/ARBs, $87.1 \% \beta$-blockers, and $95.5 \%$ statins. There were marginal numbers of patients discontinuing treatment and being initiated on treatment after discharge (Table 2). Overall, the use of aspirin ( $p=1.00)$, ACE-I/ARB $(p=0.20)$, $\beta$-blocker $(p=0.22)$, and statin $(p=0.50)$ therapies, as well as the collective use of the 5 guideline-recommended medications $(p=0.06)$, were similar at discharge and 1-month followup, whereas the use of thienopyridines declined $(p=0.02)$.
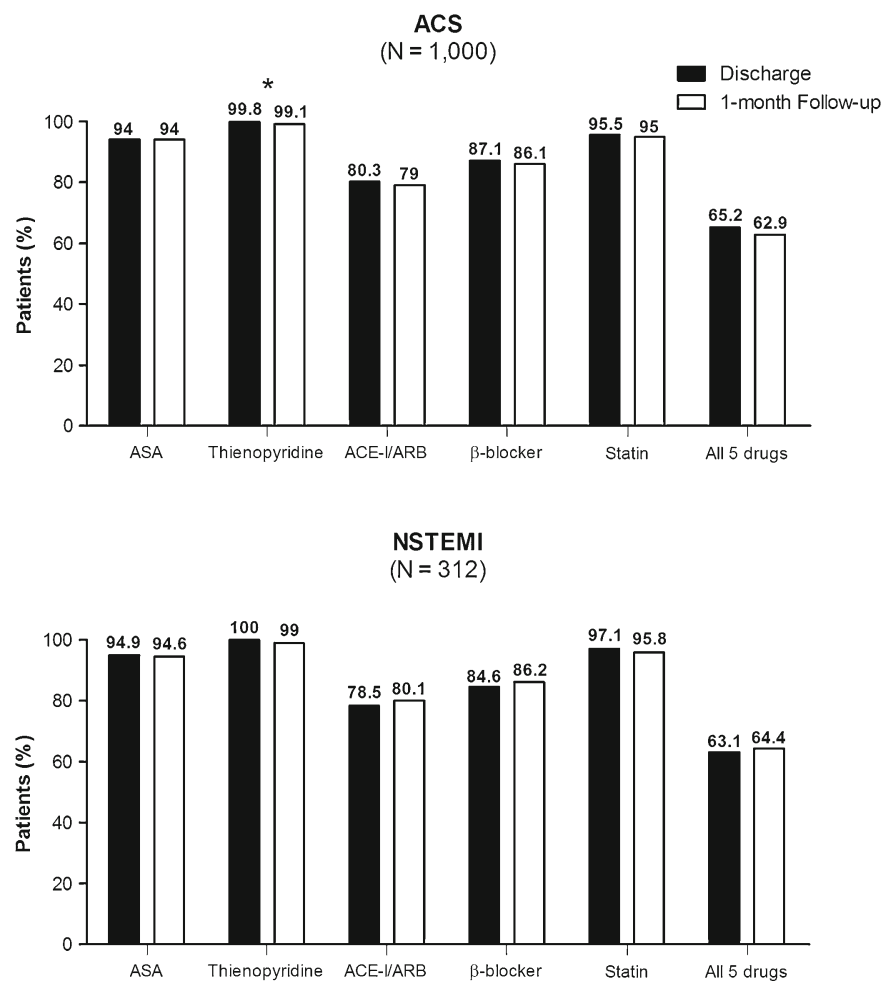

Fig. 1 Medication use at discharge and 1-month follow-up according to ACS spectrum. $* P<0.05$. ACE-I/ARB indicates angiotensin-converting enzyme inhibitor or angiotensin II receptor blocker; ACS, acute coronary
The results of multivariable analysis for the 5-drug combination therapy at discharge are presented in Table 3 . The model c-statistic and Hosmer-Lemeshow P-values were 0.69 and 0.67 , respectively, indicating good discrimination and calibration.

\section{Discussion}

The present study revealed that $65 \%$ of the PCI-treated ACS patients received all 5 guideline-recommended classes of pharmacological agents at discharge in the first subset of 1000 patients in the ongoing Dutch CCR registry. Individual utilisation rates for aspirin, thienopyridine, ACE-I/ARBs, $\beta$ blockers, and statins at hospital discharge were $94 \%, 100 \%$, $80 \%, 87 \%$, and $96 \%$, respectively, and were similar at 1-month follow-up except for thienopyridines. Importantly, STEMI and UA were the most powerful respective positive and negative predictors of the use of combination therapy at discharge. The present utilisation rates of guideline-recommended pharmacological agents represent current medical discharge management of ACS in our registry/region and serve as a baseline regional core measure performance.

Although randomised controlled trials set the 'gold standard' for evaluating treatment efficacy, observational studies
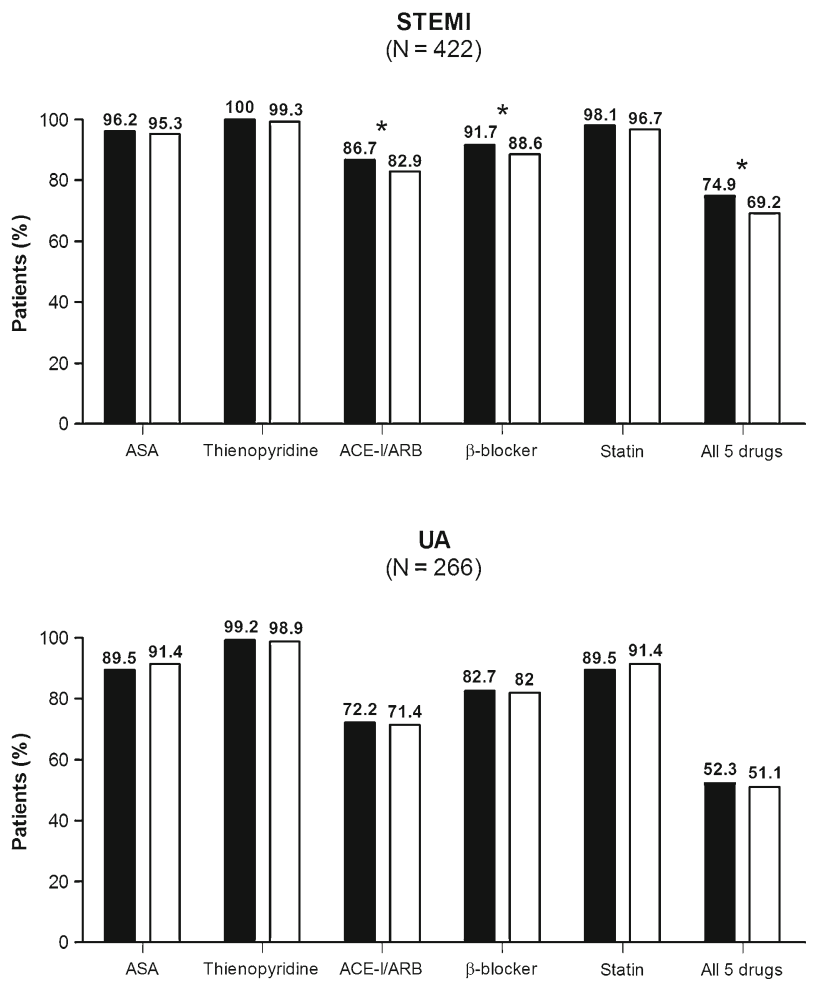

syndrome; NSTEMI, non-ST-segment elevation myocardial infarction; STEMI, ST-segment elevation myocardial infarction; and UA, unstable angina 


\section{Aspirin}

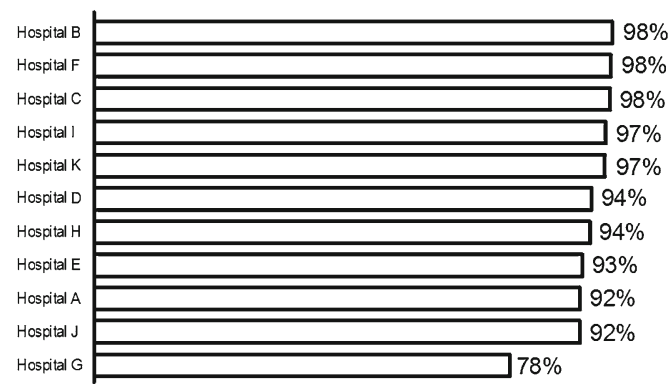

\section{ACE-I/ARB}

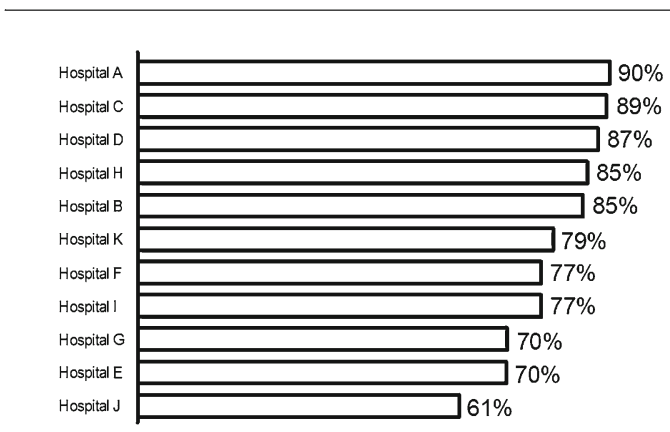

\section{Statin}

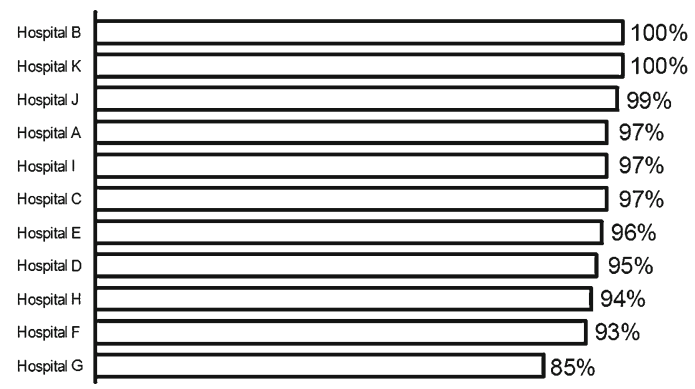

\section{Thienopyridine}

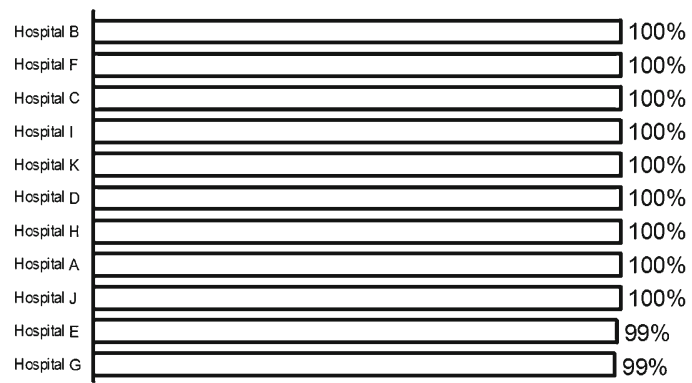

All 5

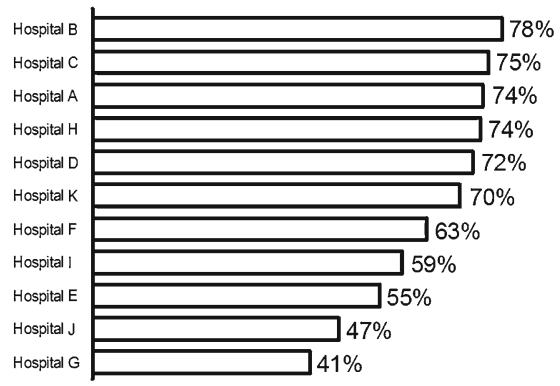

Fig. 2 Institutional discharge prescription rates. ACE-I/ARB indicates angiotensin-converting enzyme inhibitor or angiotensin II receptor blocker

afford unique and valuable insights into treatment effectiveness and generalisability in routine practice [10]. In this regard, multiple registries have demonstrated the underuse of evidence-based medical therapies at discharge among patients with ACS, irrespective of geographic location [11-15]. In these studies, 16-90\% received aspirin at hospital discharge, 17-70\% thienopyridines, 60-81\% ACE-I/ARBs, 50-90\% $\beta$-blockers, and 70-84\% statins. The collective use rates of these pharmacological agents ranged from $46 \%$ to $51 \%$. The present study indicates that both individual and collective use rates of these agents in ACS patients at discharge were reasonably high in our region compared with aforementioned registries [11-15].
The use of thienopyridines marginally decreased from $99.8 \%$ at discharge to $99.1 \%$ at 1-month follow-up corresponding to a total number of 7 patients discontinuing therapy. Nevertheless, this reached statistical significance (McNemar $p=0.02$ ). Although the exact reasons for discontinuing medications during this period are not clear, potential factors, including adverse side effects or patient compliance may constitute barriers to continuation of therapy. Of note, the 7 patients discontinuing thienopyridine therapy received either aspirin or oral anticoagulants during follow-up.

Despite the encouraging utilisation rates of 5-class combination treatment at discharge and follow-up in the present study, there is still room for improvement when considering that all 


\section{Aspirin}

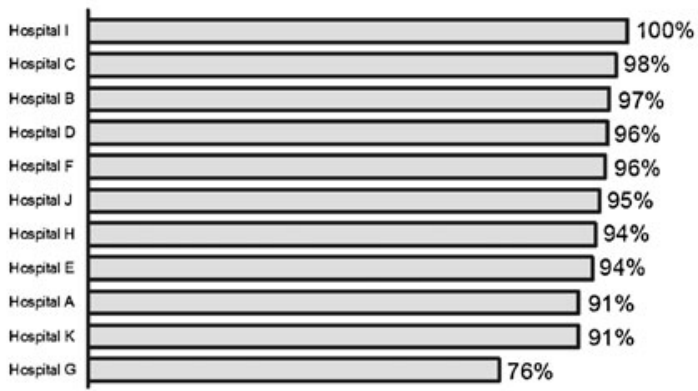

\section{ACE-I/ARB}

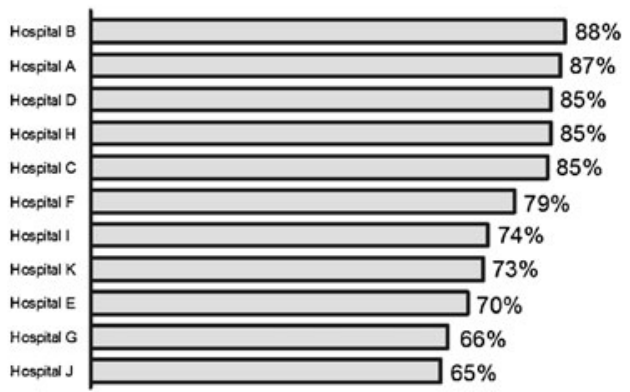

\section{Statin}

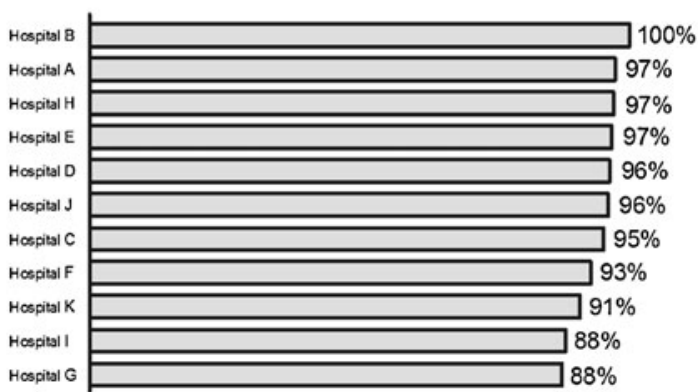

\section{Thienopyridine}

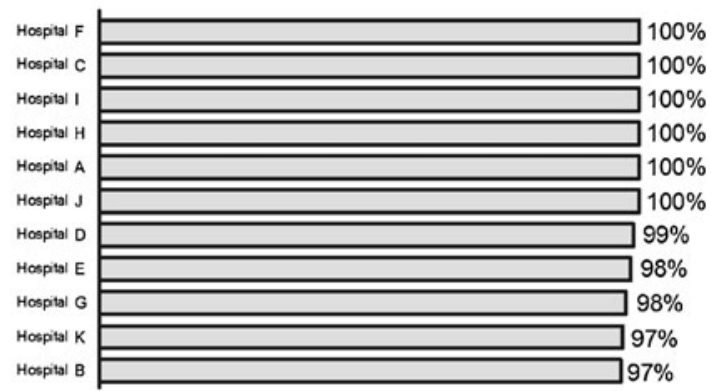

\section{$\beta$-blocker}
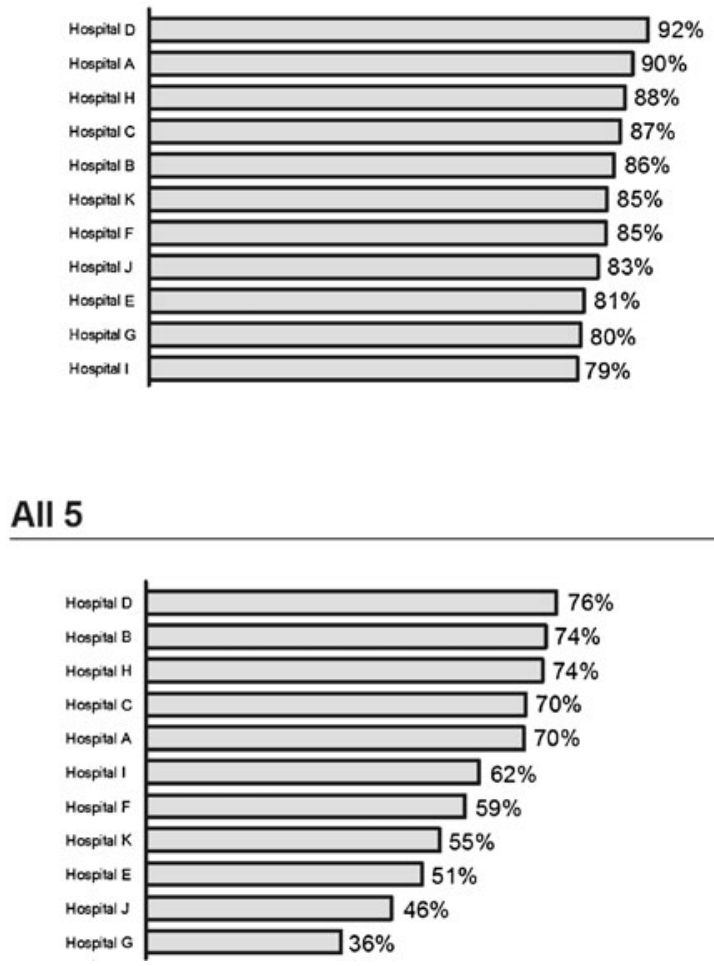

Fig. 3 Institutional follow-up prescription rates. ACE-I/ARB indicates angiotensin-converting enzyme inhibitor or angiotensin II receptor blocker

centres should reach the same level as the top 3 (Figs. 2 and 3). However, it is important to note that the absence of one of the 5 classes of pharmacological agents after ACS does not necessarily imply that patients are not treated optimally. Practice guidelines recommend the use of these agents in all patients with ACS, unless contraindicated $[3,4,6]$. For instance, significant bradycardia (heart rate $<50$ beats $/ \mathrm{min}$ ) or hypotension (systolic blood pressure $<90 \mathrm{mmHg}$ ) are contraindications to $\beta$-blockers. ACE-I are indicated in all patients with STEMI and NSTE-ACS patients with left ventricular ejection fraction $\leq 40 \%$, heart failure, diabetes, hypertension, or chronic kidney disease, however, in the absence of severe renal dysfunction (serum creatinine $>221 \mu \mathrm{mol} / 1$ in men or $>177 \mu \mathrm{mol} / 1$ in women) $[3,4]$.
Thus, patients receiving a combination of all indicated therapies are optimally treated from a clinical perspective.

Several investigators have studied the determinants of individual medication use after ACS [11, 12, 16-18]. The current report builds on prior work by demonstrating that UA was also independently associated with lower use of combination therapy at discharge, along with the previously reported negative predictor advanced age. In contrast, patients presenting with STEMI, hypertension, hypercholesterolaemia and those enrolled to the registry in an interventional centre were more likely to be given optimal medical treatment.

Recommendations from the European Society of Cardiology guidelines stress the importance of the development of regional 
Table 2 Change in medication use during 1-month follow-up

\begin{tabular}{lll}
\hline $\begin{array}{l}\text { Pharmacological } \\
\text { agent }\end{array}$ & $\begin{array}{l}\text { No. of patients being } \\
\text { initiated on therapy } \\
\text { during follow-up (\%) }\end{array}$ & $\begin{array}{l}\text { No. of patients } \\
\text { discontinuing therapy } \\
\text { during follow-up (\%) }\end{array}$ \\
\hline Aspirin & $5(8.3)$ & $5(0.5)$ \\
Thienopyridine & - & $7(0.7)$ \\
ACE-I/ARB & $5(2.5)$ & $18(2.2)$ \\
$\beta$-blocker & $5(3.9)$ & $15(1.7)$ \\
Statin & $5(11.1)$ & $10(1.0)$ \\
\hline
\end{tabular}

ACE-I/ARB indicates angiotensin-converting enzyme inhibitor or angiotensin II receptor blocker

${ }^{a}$ As $\%$ of patients who had not been prescribed therapy at discharge

${ }^{\mathrm{b}}$ As $\%$ of patients who had received therapy at discharge

and/or national programs to measure performance indicators systematically that can provide feedback to individual hospitals [3]. In accordance with these recommendations, the Netherlands Society of Cardiology (NVVC) has developed core competencies that recognise the important role of quality improvement for the management of ACS (that is, the 'NVVC! Connect' project). In this regard, the CCR registry serves as an ideal model for implementation and follow-up of measures aimed to improve institutional compliance with national quality standards. Moreover, it exemplifies a collaborative study design that employs a regional PCI registry platform, potentially enhancing hospital care quality in the context of an actively enrolling research study. In response to the current observations, the regional 'NVVC! Connect' committee will launch several initiatives to improve compliance with medical management recommendations from the ESC guidelines. Of note, pre-hospital care [19], rapid identification and risk stratification [20] of these patients are particularly relevant to this concept, because these represent equally important core competencies for effective care likely improving secondary prevention after ACS.

Table 3 Independent predictors of 5-drug combination therapy at discharge

\begin{tabular}{llll}
\hline Parameter & Adjusted OR & $95 \% \mathrm{CI}$ & \multicolumn{1}{l}{$P$} \\
\hline Positive predictors & & & \\
$\quad$ - STEMI & 2.02 & $1.43-2.85$ & $<0.001$ \\
- Enrolled in interventional centre & 1.68 & $1.26-2.26$ & 0.001 \\
- Hypercholesterolaemia & 1.65 & $1.20-2.28$ & 0.002 \\
- Hypertension & 1.61 & $1.19-2.18$ & 0.002 \\
Negative predictors & & & \\
- Unstable angina & 0.63 & $0.44-0.90$ & 0.01 \\
- Age & 0.99 & $0.97-1.00$ & 0.02 \\
\hline
\end{tabular}

$C I$ indicates confidence interval; OR odds ratio; and STEMI ST-segment elevation myocardial infarction
The current results provide a baseline measurement for discharge management of ACS in our region, and adherence at 1-month follow-up. Although initiation of evidence-based therapies after discharge is encouraging, numerous studies have documented the rapid decline in adherence to medications after hospitalisation for ACS [21, 22]. For this reason, we will perform a subsequent measurement at the end of the registry when the intended number of 4000 patients is recruited. Consequently, this will provide essential information regarding patient adherence to evidence-based pharmacological therapies at 1-year follow-up, as previously demonstrated in the Dutch MISSION! study [19]. On the other hand, we will also compare the current results with data from the following consecutive three subsets of 1000 patients. This will provide an important evaluation of patient management over time and will ascertain whether a quality gap exists in our region. This in turn may lead to new processes that help institutions meet benchmarks of quality care. More importantly, we will examine the relationship between the collective use of these agents and 1-month and 1-year outcome at the end of the registry.

The current study has several limitations that deserve comment. First, we did not collect detailed information on contraindications to medications. However, we assume that patient profiles were evaluated before institution of agents and other reasons for withholding medical therapy were probably uncommon. Second, adherence to medication was assessed at 1-month follow-up. Use rates of pharmacological agents at 1-year follow-up may vary due to discontinuation and initiation of treatment after discharge. We will address this issue at the end of the registry when the 1-year follow-up is complete.

\section{Conclusion}

The present individual and collective utilisation rates of guideline-recommended pharmacological therapies indicate that current discharge management after ACS is of substantial quality in our registry and region. However, despite high rates of use, there is still potential for quality improvement of medical management of these patients. Importantly, the CCR registry will continue to provide essential data concerning regional performance and will potentially enhance hospital care quality in the context of an actively enrolling research study.

Acknowledgments The authors are indebted to Elisabeth Huijskens for excellent execution of the monitoring. The authors would also like to acknowledge the professionalism and commitment to this registry of the staff at all interventional and referring hospitals participating in the CCR collaboration.

Funding The CCR study is supported by the Eli-Lilly Nederland B.V. and Daiichi Sankyo Nederland B.V. Other than providing financial support, the supporters had no involvement in the study design, study management, or data interpretation. The authors are solely responsible 
for the design and conduct of this study, all study analyses, the drafting and editing of this manuscript, and its final content.

Conflict of interest Financial support to the CCR study is provided by the Eli-Lilly Nederland B.V. and Daiichi Sankyo Nederland B.V. Tuncay Yetgin, Marc M.J.M. van der Linden, Arie G. de Vries, Pieter C. Smits, Rob van Mechelen, Sing C. Yap, Eric Boersma, Felix Zijlstra, and Robert-Jan M. van Geuns have all disclosed that they have no financial interests related to this article.

Open Access This article is distributed under the terms of the Creative Commons Attribution License which permits any use, distribution, and reproduction in any medium, provided the original author(s) and the source are credited.

\section{Appendix}

Participating centres Albert Schweitzer Hospital, Dordrecht; Beatrix Hospital, Gorinchem; Erasmus MC Rotterdam; Havenziekenhuis, Rotterdam; IJsselland Hospital, Rotterdam; Ikazia Hospital, Rotterdam; Maasstad Hospital, Rotterdam; Ruwaard van Putten Hospital, Spijkenisse; Sint Franciscus Gasthuis, Rotterdam; Van Weel-Bethesda Hospital, Dirksland; and Vlietland Hospital, Schiedam. All centres are in the Netherlands.

\section{References}

1. Eagle KA, Montoye CK, Riba AL, et al. Guideline-based standardized care is associated with substantially lower mortality in medicare patients with acute myocardial infarction: the American College of Cardiology's Guidelines Applied in Practice (GAP) Projects in Michigan. J Am Coll Cardiol. 2005;46(7):1242-8.

2. Melloni C, Newby LK. Risk factor management after acute coronary syndromes. Heart. 2009;95(17):1382-4.

3. Hamm CW, Bassand JP, Agewall S, et al. ESC guidelines for the management of acute coronary syndromes in patients presenting without persistent ST-segment elevation: the task force for the management of acute coronary syndromes (ACS) in patients presenting without persistent ST-segment elevation of the European Society of Cardiology (ESC). Eur Heart J. 2011;32(23):2999-3054.

4. Wijns W, Kolh P, Danchin N, et al. Guidelines on myocardial revascularization. Eur Heart J. 2010;31(20):2501-55.

5. Steg PG, James SK, Atar D, et al. ESC Guidelines for the management of acute myocardial infarction in patients presenting with STsegment elevation. Eur Heart J. 2012;33(20):2569-619.

6. Wright RS, Anderson JL, Adams CD, et al. 2011 ACCF/AHA focused update incorporated into the ACC/AHA 2007 guidelines for the management of patients with unstable angina/non-ST-elevation myocardial infarction: a report of the American College of Cardiology Foundation/American Heart Association Task Force on Practice Guidelines developed in collaboration with the American Academy of Family Physicians, Society for Cardiovascular Angiography and Interventions, and the Society of Thoracic Surgeons. J Am Coll Cardiol. 2011;57(19):e215-367.

7. Krumholz HM, Anderson JL, Bachelder BL, et al. ACC/AHA 2008 performance measures for adults with ST-elevation and non-STelevation myocardial infarction: a report of the American College of Cardiology/American Heart Association Task Force on Performance Measures (Writing Committee to develop performance measures for
ST-elevation and non-ST-elevation myocardial infarction): developed in collaboration with the American Academy of Family Physicians and the American College of Emergency Physicians: endorsed by the American Association of Cardiovascular and Pulmonary Rehabilitation, Society for Cardiovascular Angiography and Interventions, and Society of Hospital Medicine. Circulation. 2008;118(24):2596-648.

8. Brilakis ES, Hernandez AF, Dai D, et al. Quality of care for acute coronary syndrome patients with known atherosclerotic disease: results from the Get With the Guidelines Program. Circulation. 2009;120(7):560-7.

9. Yetgin T, van der Linden MMJM, Vries AG, et al. Adoption of prasugrel into routine practice: rationale and design for the Rijnmond Collective Cardiology Research (CCR) study in percutaneous coronary intervention for acute coronary syndromes. Neth Heart J. 2013;21. doi:10.1007/s12471-013-0472-1.

10. Shah BR, Drozda J, Peterson ED. Leveraging observational registries to inform comparative effectiveness research. Am Heart J. 2010;160(1):8-15.

11. Granger CB, Steg PG, Peterson E, et al. Medication performance measures and mortality following acute coronary syndromes. Am J Med. 2005;118(8):858-65.

12. Roe MT, Peterson ED, Newby LK, et al. The influence of risk status on guideline adherence for patients with non-ST-segment elevation acute coronary syndromes. Am Heart J. 2006;151(6):1205-13.

13. Cheng CI, Chen CP, Kuan PL, et al. The causes and outcomes of inadequate implementation of existing guidelines for antiplatelet treatment in patients with acute coronary syndrome: the experience from Taiwan Acute Coronary Syndrome Descriptive Registry (T-ACCORD Registry). Clin Cardiol. 2010;33(6):E40-8.

14. Javed U, Deedwania PC, Bhatt DL, et al. Use of intensive lipidlowering therapy in patients hospitalized with acute coronary syndrome: an analysis of 65,396 hospitalizations from 344 hospitals participating in Get With The Guidelines (GWTG). Am Heart J. 2010;160(6):1130-6. 6 e1-3.

15. Bramlage $\mathrm{P}$, Messer $\mathrm{C}$, Bitterlich N, et al. The effect of optimal medical therapy on 1-year mortality after acute myocardial infarction. Heart. 2010;96(8):604-9.

16. Salomaa V, Paakkonen R, Hamalainen H, et al. Use of secondary preventive medications after the first attack of acute coronary syndrome. Eur J Cardiovasc Prev Rehabil. 2007;14(3):386-91.

17. Bi Y, Gao R, Patel A, et al. Evidence-based medication use among Chinese patients with acute coronary syndromes at the time of hospital discharge and 1 year after hospitalization: results from the Clinical Pathways for Acute Coronary Syndromes in China (CPACS) study. Am Heart J. 2009;157(3):509-16 e1.

18. Lee JH, Yang DH, Park HS, et al. Suboptimal use of evidencebased medical therapy in patients with acute myocardial infarction from the Korea Acute Myocardial Infarction Registry: prescription rate, predictors, and prognostic value. Am Heart J. 2010;159(6): 1012-9.

19. Atary JZ, de Visser M, van den Dijk R, et al. Standardised prehospital care of acute myocardial infarction patients: MISSION! guidelines applied in practice. Neth Heart J. 2010;18(9):408-15.

20. Six AJ, Backus BE, Kingma A, et al. Consumption of diagnostic procedures and other cardiology care in chest pain patients after presentation at the emergency department. Neth Heart J. 2012;20(12): 499-504.

21. Gislason GH, Rasmussen JN, Abildstrom SZ, et al. Long-term compliance with beta-blockers, angiotensin-converting enzyme inhibitors, and statins after acute myocardial infarction. Eur Heart J. 2006;27(10):1153-8.

22. Lee HY, Cooke CE, Robertson TA. Use of secondary prevention drug therapy in patients with acute coronary syndrome after hospital discharge. J Manag Care Pharm. 2008;14(3):271-80. 